\title{
Temperature-indicating Paints
}

\begin{abstract}
$\mathrm{T}$
HE use of special paints, such as those containing metallic iodides, for application to bearings and other parts of machinery liable to over-heating in order to indicate such temperature increase through change in colour of the paint, has been known for some years (Pinnock, J. Soc. Chem. Ind., 38, 78; 1919). These earlier preparations were, however, only suitable for comparatively low temperatures, and also the colour change as a rule was not permanent. Paints or thermo-colours adapted for use under much more exacting conditions have been developed in Germany by the I.G. Farbenind. Akt. Ges. in connexion with its fuel research work at Oppau, including aircraft engine design (F. Penzig, Z. des V.D.I., 69-74; 1939).

The method of indicating temperature change and distribution, especially in aircraft engine cylinders, etc., by means of thermo-colours offers many advantages over the usual laborious method of taking several individual temperature measurements in various parts of the cylinder, piston, etc.; and in the case of air-cooled engines it provides invaluable information in the optimum design of air guide plates. It is also of great value in other cases of temperature determination, for example, in hot plates, radiators, drying chambers, etc.

It was desired to discover paints which would not only undergo sharp, distinct, and permanent colour change at fairly definite temperatures, but would also possess good adhesion at these high temperatures, up to $450^{\circ} \mathrm{C}$. It is hoped, indeed, to evolve thermocolours for use up to $650^{\circ} \mathrm{C}$. or even higher; but those so far discovered are sufficient for present-day aircraft engine research. In regard to sharpness of change, it is obvious that intermediate tones are to some extent unavoidable since the change is due to thermo-chemical reaction; but with sufficient time the change is definite and complete. On the other
\end{abstract}

hand, allowance must be made for the fact that the longer the time exposure the lower the temperature, within reasonable limits, at which the change occurs. Curves are given in the original showing temperature change at intervals of $30 \mathrm{~min}$. up to $120 \mathrm{~min}$. for the various paints. The time effect is greatest at the higher temperatures : for example, a thermo-colour which by definite colour change indicates a temperature of $360^{\circ} \mathrm{C}$. in 30 minutes, falls to $290^{\circ}$ at $120 \mathrm{~min}$., whilst the curves at $40-80^{\circ} \mathrm{C}$. are nearly horizontal.

No fewer than three hundred different preparations have been investigated at Oppau; but only a very limited number have been found of practical use. These are tabulated by number in the original. The following are some of the colour changes: No. 1, rose to blue, $30^{\circ}$; No. 3 . light yellow to violet, $110^{\circ}$; No. 8, white to light brown, $340^{\circ}$; No. 9 , violet to white, $440^{\circ}$. No. 20 has two different colour changes at $65^{\circ}$ and $145^{\circ}$; whilst Nos. 30 and 31 have three distinct colour changes at temperatures ranging from $65^{\circ}$ to $220^{\circ}$ (No. 30), and $155-275^{\circ}$ (No. 31). The temperatures are indicated with an accuracy within $\pm 5^{\circ}$, which is sufficiently accurate for the purpose in view. Where exact measurement is required at any particular point this can be done in the usual way with thermo-elements.

The binding agent or medium used presented some difficulty; it was eventually discovered that a synthetic resin soluble in alcohol is the most satisfactory. It is added in finely powdered form to the pigment, and a paint of any desired viscosity may be prepared by stirring this mixture with the correct amount of alcohol. These paints dry very quickly, the resin does not undergo any colour change which would affect the desired result, and the paint coating has practically no influence on heat transference from the cylinder or other part under test.

\section{Testing High-Voltage Cables}

$\mathrm{T}$ $\mathrm{HE}$ use of high-voltage cables for the underground transmission of electric power is becoming more and more important from the point of view of economy, and also because as the network extends the damage caused by the breakdown of a cable, generally due to over-voltage, may be very serious. For the last ten years constant research has been proceeding, dealing with oils, papers and the general physics of cables. In the development of a cable suitable for extra-high voltage transmission there have been four main methods of attack. The first is to use oil-filled cable, the second external gas-pressure cable, the third internal gas-pressure cable (gas-filled cable), and the fourth the cables most commonly used with solid insulation known as 'solid cables'.

In a paper read to the Institution of Electrical Engineers on January 18, by T. R. Scott and R. C. Mildner, the results are described of researches extending over several years on a 3 -core $30 \mathrm{kv}$. solid cable which has since, without any fundamental change, been manufactured in considerable quantity and has given extremely satisfactory service. Singlecore cable manufactured on identical lines was somewhat inferior in performance. At $60 \mathrm{kv}$. this difference became very noticeable, although on the basis of standard acceptance tests there was little or nothing to choose between multi-conductor and single-conductor cables. It became evident, therefore, that some form of final check approximating to 'trial on service' was necessary to ensure that unsatisfactory types of cable were not issued for commercial service. In view of the destructive nature of the test that was visualized, it was considered impracticable to instal the cable in the network of an operating company. It was considered feasible to design a testing plant to reproduce all the conditions under which cables operated, and yet give the facilities which such a research requires. It was realized that such a method 
would be slow to produce results and expensive to carry out; but its value has been amply proved by the practical results achieved.

Solid-core $60 \mathrm{kv}$. cable was originally selected as the basic type. It was considered that this type of cable would always be able to compete on an economic basis with the other forms of cable that have been proposed, provided that it could be proved that it was capable of operating at a conductor temperature not less than $65^{\circ} \mathrm{C}$. for a life not appreciably less than that of solid cables operating at lower voltages. Work on solid-type $60 \mathrm{kv}$. cables also provided an excellent basis not only for effecting improvements in the performance of similar cables working at $30 \mathrm{kv}$. and lower voltages, but also for extending the investigation to $132 \mathrm{kv}$. All experimental cables were 'processed' in the factory under closely observed, but essentially practical, conditions, and their characteristics have been watched carefully throughout their useful life. The paper gives a preliminary survey of the work carried out to date.

It is hoped that the results obtained will assist in allaying certain fears which obviously influence cable users. The authors state that as the result of the experience gained in their tests the successful operation of solid-type cable at $60 \mathrm{kv}$. has been firmly established. The employment of this form of cable in preference to the other types which have been proposed, should rest on a purely economic basis in which the cost of the installed line and its maintenance is added to the charges to be attributed to the electrical losses involved in operation. In this latter respect the stability of the dielectric need be in no way inferior to that of other types. It is pointed out that the deterioration due to the electric discharges in vacuum spaces (gas pockets) can be reduced to negligible proportions at the proposed working stresses by due attention to the quality of manufacture. In this matter the authors' experience suggests that 'uniformity of impregnation' is the main object to be aimed at rather than getting the purest material. As the 'geometric factor' of the cables tested varies widely, it is concluded that the maximum electric stress in the cable is the crucial factor in its behaviour in operation.

\section{University Events}

BIRmingham.--The following honorary degrees are to be conferred at the degree congregation on July 1 : LL.D. on Mr. A. C. Beatty, Lord Porter, and Sir Charles Grant Robertson; D.Sc. on Dr. E. B. Bailey, and Sir William Bragg; D.Litt. on Prof. Arnold J. Toynbee.

Cambridge.-The tenth course of Scott Lectures are being given in the Cavendish Laboratory by Prof. P. M. S. Blackett, at 4.30 p.m. on May 4, 5 and 8 . The subject of the lectures is "Cosmic Rays-New Results and Further Problems".

W. S. Tai, research student of Gonville and Caius College, has been elected to the Sheepshanks exhibition.

London.- The Farnham House Laboratory of the Imperial Institute of Entomology, at Farnham Royal, Bucks, has been approved as an "Institution having Recognised 'Teachers" for the instruction of students pursuing courses of advanced study or research.

\section{Science News a Century Ago}

\section{Ptolemy's Catalogue of Stars}

Ar a meeting of the Astronomical Society held on May 10, 1839, Francis Bajly, in a paper bearing the above title, said: "The catalogue of stars, which goes under Ptolemy's name, will always be interesting to the astronomer, as containing the first record of the state of the heavens. The point to which, in the present view of the case, I am most desirous of directing attention is, how far the existing edition of this work may be considered as faithful transcripts of the catalogue as it issued from Ptolemy's hands. This important question can only be decided by a careful examination of various manuscripts, and by comparing the discordant readings with the actual positions of the stars, as determined by modern observations." Having referred to the five sources of information, he went on: "Having carefully compared the position of every star, as given in each of the several copies alluded to, I have found that out of 1,028 stars, of which the catalogue consists, there are above 780 (or more than three-fourths) of them that are discordant, either in longitude or latitude, and this not merely in 10,20 , or 30 minutes, which is no uncommon difference, but sometimes to an amount involving whole degrees."

\section{The Atlantic Voyage of the Ironsides}

In October 1838, Airy, at the request of the owners of the iron sailing ship Ironsides, had made improvements in the method of correcting her compasses. Shortly afterwards, the ship sailed for South America. After her return, the Mechanics' Magazine on May I1, 1839, said: "This, the first sailing vessel constructed of iron which has ever been dispatched to encounter the risk of a transatlantic voyage, and which left Liverpool some five months since, for the Brazils, entered the Mersey on the Ist of May. The homeward passage from Aricati was accomplished in forty days, which is considered to be no despicable achievement, as during the whole trip light winds prevailed. The return of the Ironsides, has completely established the practicability of navigating the ocean safely and surely in ships constructed of iron. The compass, whose action it was predicted would invariably be deranged, worked correctly; and the superiority of the material of which she is built is proved by the fact, that from the day on which she sailed for Pernambuco, during the time she remained at the Brazils, and in the course of her voyage home, on no one occasion was it necessary to use the pumps; in fact her hull is absolutely and literally water tight."

\section{The Asiatic Society}

Among the reports read at the sixteenth anniversary meeting of the Asiatic Society on May 11, 1839, was one by the Right Hon. Holt Mackenzie referring to the work of the Committee of Commerce and Agriculture. It commenced by acknowledging the valuable services of Dr. Royle (secretary) and Mr. Solly (chemical analyst). Attention, it said, had been given to the introduction into India of improvements in cotton cultivation; the value and quality of various oil seeds grown in India and the vegetable tallow of Canara; and information had been collected regarding caoutchouc, kino, hemp, tea, iron, cochineal, timber, wool, silk and other things. 